Armando Zegri.

\title{
El último decadente
}

Novela.-Paris (Ediforial

Le livre libre).

\section{CAPITULO IV.}

ODRÍGUEZ consultó impaciente el reloj. - ¿Qué hora?, murmuró Sarvia, que seguía de cerca a su amigo.

- Las ocho y media.

-Vamos bien.

De la puerta del teatro de La Comedia, siguieron hasta la esquina. Sarvia llamó un automóvil.

-No, exclamó Laura Galdós, tirándole del brazo, mejor una victoria. Me resulta más romántica para viajar de noche.

Los hombres rieron de la ocurrencia. A un auriga próximo indicaron la dirección de Dalia de Rodas y subieron al carruaje.

Durante todo el trayecto, Rodríguez no dijo una palabra. Las calles del centro parecían llenas de gente. Una banda militar tocaba retreta en la plaza de armas. $\mathrm{Pa-}$ saron frente al cerro Santa Lucía y siguieron por el la- 
do derecho de la Alameda. Dalia vino a recibirlos a la puerta. La primera sala estaba llena de humo, de voces y de cojines. Sentados en un diván con cubierta de telas indigenas, Aliro Ordax y Elena Ceballos charlaban, fumando cigarrillos. César Dávila, que oía la conversación, se levantó para ir a saludar a Rodríguez. Elena Ceballos era una mujer madura, alta, maciza, sólida y no poco atrayente. A juicio de algunas personas, había nacido para realizar en la vida dos funciones de igual importancia: hablar de arte y enamorarse de los artistas. Entre la mayor parte de sus amigos, Aliro Ordax merecía el título de fipo raro. Había viajado, y de sus viajes, conservaba una manera de ser cosmopolita. Su voz era ronca, áfona y contrastaba, al vibrar, con el desfallecimiento casi femenino de sus ademanes. Vestia generalmente de negro y la palidez de su rostro tenía el color amarillo oscuro de la cera. La historia de su vida comenzaba a la edad de veintitrés años. A la muerte de su padre, se trasladó a Santiago, armado de una pequeña fortuna. Hizo amigos en los círculos literarios: y las reuniones en su casa de la calle Catedral llegaron a adquirir cierta maliciosa notoriedad entre la gente joven. Pero la vida de la capital-vida de aldea en grande, como él la llamaba-empezó pronto a aburrirle. Inesperadamente, una noche, mientras cenaba en el Círculo Español, anunció que había decidido cambiar de domicilio: se iba al día siguiente a Buenos Aires para tomar un vapor a Nueva York. Después se supo que la aglomeración, la simetría, el ruido y el orden de Nueva York le habian, en quince dias, destruido los nervios. Estuvo tres semanas en Londres y lué definitivamente a 
establecerse a París. Todo lo que había traído lo gastó en un año entre Montmartre y la Plaza de la Opera. Nadie supo en qué forma hizo el regreso a Chile. Una tarde apareció en la esquina de Huérfanos frente al teatro de La Comedia. Desde entonces su vida fué una serie de discursos, trasnochadas y paraísos artificiales. Aliro Ordax era un hombre que sabía conversar. Estaba muy bien armado de cultura, de palabras y de perspicacia para las polémicas. A pesar de la insistencia de sus mejores amigos, jamás se había propuesto escribir y menos publicar nada de lo que improvisaba en las conversaciones. Debido al abuso de los alcaloides, sus ojos empezaron a hundirse en un círculo morado y parecian mirar desde muy lejos. Durante algún tiempo habia defendido y elogiado la personalidad de Oscar Wilde en las reuniones literarias. Pocos como él dominaban la obra del escritor inglés y conocian a fondo hasta los detalles más íntimos de su biografía.

- Chile es un país tranquilo, un lugar ideal para morir. respondía Ordax a todas aquellas personas que no habian visto otro cielo que el del terruño y no se explicaban el hecho de pasar por todas las molestias de un viaje a Paris para ir a terminar nuevamente en un pueblo de la América del Sur.

Dalia ordenó pasar al comedor. Los invitados se levantaron para seguirla. La mesa estaba cubierta de frulas, de cristales, de flores y de botellas. Las paredes eran de piedra oscura y las sillas sugerian, en lineas generales, el asiento de los confesionarios. El respaldo estaba formado de una sola tabla labrada que subia so- 
bre el nivel de las cabezas. Los demás muebles eran pesados y sobrios.

-Está usted muy bonita esta noche, murmuró Rodríguez, que había ido a sentarse al lado de Dalia de Rodas.

-Lisonjero...

Esta es una de las pocas veces que experimento la necesidad de ser expansivo. Créame..., insistió Rodríguez, mientras cortaba nerviosamente con los dedos los tallos de las flores que estaban cerca de su plato.

Dalia se rió con los ojos, e inclinándose para colocarle una gardenia en el ojal de la solapa, prefiero dudarlo le dijo, echándole, junto con las palabras, todo el aire de su boca caliente en la cara.

Rodríguez quiso responder algo, pero no supo qué. $Y$ su esfuerzo se tradujo en una sonrisa. En el ofro extremo de la mesa Elena Ceballos. Aliro Ordax y Laura Galdós charlaban animadamente.

-Usted nunca habla de su niñez ni de sus amores, insinuó Elena, haciendo una señal a Laura Galdós, que había vuelto los ojos para mirarla. Esos dos estados que el hombre debe necesariamente atravesar para merecer el caliticativo de Hombre con mayúscula.

- La razón es muy sencilla, respondió Aliro. Mi niñez es una página en blanco. En cuanto al amor, creo que hay necesidad de una clave para enamorar a las mujeres. Algunos hombres nacen con ella: Casanova y Lord Byron, por ejemplo. Otros mueren sin haberla jamás descubierto. Yo me encuentro entre los que todavía ignoran la fórmula.

-No me explico... 
- Ni vale la pena, continuó Aliro riendo. Las explicaciones sirven sólo para presentar los objelos con sus defectos.

-Deja usted de ser sincero, intervino Laura Galdós.

- La verdad es por sí sola una paradoja, contestó Aliro mirando a la mujer.

Ocupémonos mejor de ofros asuntos, dijo Elena Ceballos. Para disculir con Ordax es necesario correr sobre un plano inclinado, con la misma velocidad hacia arriba que hacia abajo.

La charla en torno a la mesa se hacia cada vez más viva y más alegre. Cuando se descorchó la primera botella de champagne, Pedro Sarvia propuso la idea de beber la primera copa en honor de alguien. Cada comensal podía sugerir uno o varios nombres, y el nombre que tuviera más éxito se ganaba el brindis. Pero la elección fué difícil; no era posible arribar a ningún acuerdo. César Dávila propuso beber por la serpiente bíblica, por la serpiente con patas del Paraíso Terrenal. Dalia apoyó la idea, diciendo que la serpiente había creado en el primer hombre una virtud esencial: la curiosidad. Pedro Sarvia y Elena Ceballos hicieron la oposición. Después se pasó revista a la mitología. Aliro se opuso a la candidatura de Satanás. Dijo que era una Calta de galantería; su triple aspecto de hombre, de carnero y de murciélago repugnaba a las mujeres. El ambiente estaba lleno de carcajadas. Se habían bebido la tercera copa de champagne sin recordar el plan propuesto antes de la primera.

-Y tú ¿no dices nada?, murmuró Dalia, dejando el vaso para mirar a Rodríguez. 
- Se han acaparado todas las tonterías, respondió éste, designando con un movimiento de los ojos a las demás personas en la mesa.

-No te incomodes, insistió Dalia, pegándole con una flor en la mejilla. Si algo digo no es porque me indigna, sino porque me intriga tu reserva.

En lugar de contestar, Rodríguez se limitó a mirarla codiciosamente. En realidad, él se sentía molesto en aquel grupo de charladores que todo lo sacrificaban al efecto de una frase ingeniosa. Las preguntas lo turbaban. Le parecía que foda la reunión estaba pendiente de lo que iba a decir. Hubiera querido encontrar alguna excusa para retirarse. Pero le faltaba voluntad para exponer un pretexto en voz alta. En semejante estado de ánimo se mantuvo hasta el final de la comida.

\section{Elena Ceballos cerró el piano.}

- Bastante, exclamó, levantando el brazo para consultar la hora. Y son las cuatro de la mañana. Creo que ha llegado el momento de retirarnos. Es demasiado tarde.

- Es decir, demasiado temprano, corrigió Aliro Ordax parodiando una frase de Barbey d'Aurevilly.

Elena dió una vuelta en el asiento para mirarle riendo:

- Es usted insoportable. Un día le va a vender el alma al diablo por una docena de palabras.

La atmósfera del cuarto estaba cargada de humo de cigarrillos y esencia de licores. Pedro Sarvia y Laura Galdós se habían retirado poco después de terminada 
la comida. Entre Aliro, Dalia, Elena y César Dávila el mundo sufrió una revisión teórica de pies a cabeza. Rodriguez fumaba y bebía, persiguiendo con los ojos todos los movimientos del cuerpo de su amiga. Para terminar una de las discusiones, Elena se acercó al piano. - Algo de Chopin, sugirió César Dávila.

-A Chopin prefiero un disco de jazz en la victrola. interrumpió Aliro.

- Qué bárbarol dijo Elena, haciendo ademán de tirarle con un libro de música. .

- Aliro inventa todo el tiempo algo para escandalizar, intervino Dalia. La dificultad está en admitir que dice las cosas en serio.

- Si este siglo ha creado alguna melodia, respondió Ordax, encendiendo un cigarrillo, ha creado la melodía del ruido. El alma del hombre, harta de civilización, vuelve a tomarle cariño a las artes populares. En música, mientras más lejos se camina hacia atrás, en dirección a lo primitivo, el ruido se hace más elemental. Y el jazz se ha servido precisamente de este ruido elemental para expresar la histeria mecánica del siglo. Es el lenguaje musical de la época. ¿Usted se ríe?, continuó, dirigiéndose a Dalia, que desde la primera palabra lo había escuchado con una sonrisa. Hoy día no se puede ignorar la presencia de la máquina. En las grandes casas de comercio de Nueva York cuando un empleado vende un pedazo de casimir, por ejemplo, no necesita medir ni calcular el precio del artículo. Ajustado al mostrador tiene un pequeño aparato que corta la tela y le indica al mismo tiempo el valor de la cantidad de material que ha vendido. Éste es, indudablemente, el 
primer paso al descubrimiento de la máquina que nos librará de la molestia de pensar.

- Pero ¿qué conexión tiene todo esto con la música de Chopin?, preguntó Elena,

- Ninguna, dijo Aliro. Diferencia únicamente la expresión musical de un siglo pasado con la del nuestro. La música de Chopin sugiere casi siempre una escena con lágrimas. ¿Y a quién puede interesarle hoy un lamento, cuando las ciudades están llenas de pitos a vapor?

Después del punto de interrogación final, la sala se llenó de carcajadas. Elena, para molestar a Ordax, empezó a tocar la Marcha Fúnebre. Era tarde y decidieron irse. Dalia los acompañó hasta la puerta. Salieron en grupo, llenando el pasadizo y después la calle de exclamaciones y de risas. Nadie advirtió la ausencia de Rodríguez, y cuando Dalia volvió al interior, encontró a éste parado en medio del cuarto. Los ojos de Dalia expresaron sorpresa. La actitud de Rodríguez parecía resuelta, a pesar de la nerviosidad con que apretaba las manos. Dalia no dijo una palabra; pero lo miró interrogándolo con la mirada.

- Perdóneme... titubeó Rodríguez. La esperaba... No quise marcharme sin verla un instante a solas.

Dalia de buenas ganas se hubiera reido, porque la sifuación estaba tomando un aspecto tragi-cómico. Pero el sonido de la voz de Rodríguez la contuvo: la voz expresaba vencimiento, deseo y ruego. El cuarto eslaba todavía lleno de humo y de las copas se levantaba un aroma fuerte de licores. A Rodríguez le parecía que sus piernas se habían transformado en dos columnas de piedra que lo sujetaban al suelo. Las ideas daban vuelta 
rápidamente en su cabeza, produciéndole calor y mareo. Dalia volvió a mirarle, y Rodríguez sostuvo la mirada sin articular palabra. El tiempo pasaba muy lento, con una lentitud atroz: con el tamaño de cada minuto se hubiera podido medir la elernidad. Por primera vez sintió - Dalia que, a solas, la presencia de Rodriguez la turbaba. Quiso ir a un extremo del cuarto, y algo la hizo vacilar.

-Bien, exclamó por fin acercándose más a Rodriguez. ¿Tiene algo que decirme?

-Rogarle que me perdone... Y... no pudo terminar la frase. Le faltaba coraje. El sonido de las palabras se ahogaba detrás de la muralla de sus dientes. De haber podido, se hubiera roto los dedos para calmar la inquietud de sus nervios.

Dalia levantó una vez más los ojos: el hombre era bello, fuerte; la sangre caliente le quemaba las mejillas. Toda su aclitud revelaba lo que le habia dado a conocer ya muchas veces: una gran pasión contenida. Repentinamente y sin darse cuenta, le rodeó el cuello y lo besó en los labios con ansia. Creyeron oir ruido de pasos. Dalia retiró los brazos y condujo a Rodríguez hasta la puerta de calle. Éste se afirmó coníra la muralla por un largo rato antes de poder dar un paso. Se sentía ebrio de una ebriedad que no conocia. 